\title{
O ESTÁGIO DOCÊNCIA COMO OPORTUNIDADE DE VIVENCIAR A SALA \\ DE AULA ${ }^{1}$
}

\author{
Débora Costa Nunes Lopes ${ }^{1}$ \\ Rafaella Buso Santos ${ }^{2}$ \\ Diva Souza Silva ${ }^{3}$
}

\section{RESUMO}

A presente pesquisa faz parte das investigações ligadas ao Grupo de Estudos e Pesquisas em Didática e em Desenvolvimento Profissional dos Professores da Universidade Federal de Uberlândia. Tem como objetivo realizar diagnóstico das contribuições do Estágio em docência para a formação do pós-graduando com relação à dimensão didático-pedagógica. Os processos metodológicos envolvem a revisão bibliográfica; análise documental; aplicação de instrumentos; observação de aulas; análise e discussão dos dados. Os resultados até então apontam a ausência de políticas públicas para formação destes professores; o estágio docência tem carga horária pouco expressiva e a formação está focada na competência cientifica desprovida da dimensão didáticopedagógica, contudo constitui-se por vezes como primeiro contato com a sala de aula.

Palavras Chave: Docência na Educação Superior; Estágio Docência; Saberes e Práticas.

\begin{abstract}
This research is part of the investigations related to the Group of Studies and Research in Teaching and Professional Development of Teachers of Federal University of Uberlândia. It aims to conduct diagnosis of Stage contributions in teaching for the training of graduate student regarding the didactic and pedagogical dimension. Methodological processes involve literature review; document analysis; enforcement instruments; classroom observation; analysis and discussion of data. The results so far point to the absence of public policies for training of these teachers; the teaching stage has little significant workload and training is focused on the scientific competence devoid of didactic and pedagogical dimension, however It is sometimes as first contact with the classroom.
\end{abstract}

Keywords: Teaching in Higher Education ; Teaching Internship ; Knowledge and practices .

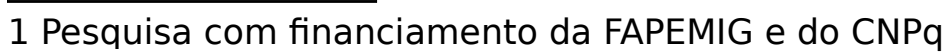

${ }^{1}$ Discente do curso de Pedagogia da Universidade Federal de Uberlândia - UFU; Bolsista CNPq em projeto de Iniciação Científica. deboracnlopes@hotmail.com

${ }^{2}$ Discente do curso de Pedagogia da Universidade Federal de Uberlândia - UFU; Bolsista FAPEMIG em projeto de Iniciação Científica. rafaella buso@hotmail.com

${ }^{3}$ Doutora em Educação; Professora adjunta na Faculdade de Educação - FACED da Universidade Federal de Uberlândia - UFU. diva@faced.ufu.br 


\section{INTRODUÇÃO}

A Educação Superior é tema ainda pouco recorrente em congressos, estudos e pesquisas, mesmo considerando a necessidade de formação desses profissionais nesse nível de ensino. É reconhecido o papel crucial do professor e de sua formação no desenvolvimento de um sistema educacional de qualidade, adequado às exigências do momento histórico atual. E para tanto, há a necessidade de se conhecer o que as instituições de formação do docente da Educação Superior têm realizado nos seus programas de pós-graduação, como também os resultados de suas produções. Isso pode ser indício de valorização e reconhecimento da importância da docência na Educação Superior como fator resultante na qualidade da formação dos alunos formados nas instituições.

Nos últimos anos o cenário que se descortinou na Educação Superior apresenta uma série de desafios concernentes à ampliação do número de vagas, criação de novos cursos em função do processo de expansão desse nível de educação. Aliado a esse cenário está o crescente número de concursos para docentes que chegam às universidades com pouco preparo para o exercício da docência, conforme foi possível constatar em uma pesquisa realizada por nós, intitulada “A socialização profissional de professores e o desenvolvimento da identidade docente no Ensino Superior” (MELO et. all. 2011). Embora a universidade se constitua no principal espaço formativo para profissionais de diferentes áreas, destacamos pelo menos um aspecto no qual tem se mostrado ineficaz: a formação de professores para atuar nas diferentes etapas e modalidades da educação, principalmente, no ensino superior. Tais práticas baseiam-se no entendimento de que o domínio dos saberes técnicos da profissão seja suficiente para autorizar legalmente um individuo diplomado a assumir a docência como profissão.

Se por um lado a formação de grande parte dos docentes universitários não contempla questões relacionadas ao exercício da profissão docente, por outro, será fundamental criar nas universidades espaços para discussão e reflexão a respeito da docência e dos desafios enfrentados no exercício dessa profissão. O objetivo desse processo será buscar um melhor entendimento a respeito do sentido formativo da instituição e do compromisso dos docentes com a melhoria da qualidade da formação pessoal e profissional de seus estudantes. 
A função da universidade historicamente passa por transformações. Há, no imaginário social, cada vez mais, a atribuição de um valor peculiar ao conhecimento, no qual a universidade ocupa dupla tarefa: a de produzir e disseminar os conhecimentos nas diferentes áreas. Nesse sentido, o trabalho do professor universitário consiste, também, em contribuir efetivamente para que os estudantes aprendam a superar a razão instrumental, fruto de vários anos inseridos numa cultura escolar que privilegia o empirismo e o cientificismo, em detrimento do pensamento crítico pautado por uma sólida formação teórica nas humanidades. Ao professor caberá a tarefa de despertar nos estudantes a capacidade inventiva, a criatividade, a dúvida metódica, a curiosidade epistemológica (FREIRE, 1996) e a expressão crítica da realidade. Esse processo deverá propiciar a formação de um profissional preparado para enfrentar um mundo de mudanças e incertezas (IMBERNÓN, 2002), no qual é exigido o desenvolvimento de saberes técnico (específicos para o exercício da profissão), além de saberes relacionados à convivência humana, dado que somos seres sociais e as profissões, em sua maioria, são exercidas em contextos coletivos.

A partir da constatação referente à importância dos saberes docentes, fica evidente a necessidade de que os cursos de formação de professores passem a considerar a importância destes saberes no processo formativo, principalmente nos cursos de formação inicial, em que os licenciandos começam a ter os primeiros contatos com a profissão. Diferentes estudos, dos quais destacamos: Altet (2001), Charlot (2002), Nóvoa (1995), Sacristán (2002), Schön (1992), Zeichner ( 1993) vêm sendo realizados na América do Norte, Espanha, França e Portugal, com repercussões em outros países e no Brasil. O modelo da racionalidade técnica e as abordagens psicológicas que se centravam nos processos de aprendizagem, não mais satisfazem as inquietações dos pesquisadores na área educacional. Isso faz com que se volte um olhar diferente para a problemática educacional e, especificamente, para a docência nos diferentes níveis de ensino buscando compreender o professor comosujeito histórico, dotado de subjetividades e intencionalidades.

Nessa perspectiva, o saber docente vem sendo utilizado como importante categoria de análise, que busca desvelar o entendimento da cultura escolar, da prática pedagógica, enfim, dos saberes de que se utilizam os professores em seu cotidiano. Diante deste cenário delimitamos como objeto de investigação o Estágio Docência, que 
a partir de 1999 foi inserido de forma obrigatória pela Coordenação de Aperfeiçoamento de Pessoal do Ensino Superior, para os alunos bolsistas dos cursos de Pós-graduação stricto sensu. Para tanto iremos empreender uma pesquisa de caráter qualitativo.

\section{DESENVOLVIMENTO}

Nossa intenção com essa temática será a continuidade da investigação em uma abordagem qualitativa, pois esta nos permite uma diversidade de enfoques para compreender o objeto de estudo. A abordagem qualitativa de pesquisa requer do pesquisador uma atitude sempre indagativa, na qual "o exercício da curiosidade convoca a imaginação, a intuição, as emoções, a capacidade de conjecturar, de comparar, na busca da perfilização do objeto ou do achado de sua razão de ser" (FREIRE, 1996, p. 98). Mas, não uma curiosidade qualquer, segundo Freire, ingênua, e sim uma curiosidade epistemológica, que busca o rigor das análises, que não se contenta com o aparente, com o superficial, mas que persegue, por meio da consciência crítica, os indícios e vestígios do objeto até alcançar a respostas das questões problematizadas.

A pesquisa qualitativa, segundo Bogdan e Biklen (1994) refere-se à análise dos dados de forma indutiva. Segundo os autores citados, o investigador não recolhe dados com o objetivo de confirmar hipóteses construídas previamente, pelo contrário, as abstrações são construídas à medida que os dados vão sendo coletados e categorizados.

Isso significa que é no curso da investigação, ou seja, no decorrer do processo que o objeto de pesquisa começa a ser compreendido e delineado. Esse movimento exige do pesquisador a capacidade constante de rever os caminhos, de questionar os instrumentos de coleta de dados, pois não há como reconhecer o essencial do que é secundário antes de iniciar a investigação. Além disso, "o processo de condução da investigação qualitativa reflete uma espécie de diálogo entre os investigadores e os respectivos sujeitos, dado estes não serem abordados por aqueles de forma neutra" (Bogdan e Biklen, 1994, p. 51). Isto porque as análises são carregadas de sentido e de intencionalidades pelo pesquisador e não há, portanto, como ser neutros ou mesmo imparciais, o que requer do pesquisador uma maior acuidade no sentido de compreender o objeto de pesquisa sem se deixar contaminar por pré-julgamentos ou evidências aparentes. 
Esta pesquisa esta sendo desenvolvida sob a ótica da iniciação científica, sendo a sua finalidade: analisar as contribuições do Estágio docência para a formação do pósgraduando com relação à dimensão didático-pedagógica. Para tal iremosavaliar a configuração do Estágio em docência nos Programas de Pós Graduação da Universidade Federal de Uberlândia a partir do mapeamento da distribuição da carga horária, atividades desenvolvidas, orientações, e da quantidade de discentes matriculados na disciplina. Buscando destacar e analisar as principais dificuldades enfrentadas pelos pós-graduandos ao desenvolverem o estágio em docência assim como identificar os saberes docentes, assimilados e utilizados na prática cotidiana pelos pós-graduandos no decorrer do estágio docência. Deste modo almejamos contribuir com elementos teóricopráticos para a discussão da formação na pós-graduação stricto-sensu no País, especificamente, na instituição de ensino superior em questão.

A pesquisa do estudo aqui referido segue um desenvolvimento horizontal no período de dois anos, os pós- graduandos que participarão da pesquisa serão escolhidos conforme forem ingressando no estágio docência ou similar por meio de um questionário por nos elaborado. É importante aqui ressaltar que os pós-graduandos não são nosso objeto de pesquisa, mas sim o processo de formação docente na experiência de estágio de docência. O pós-graduando é apenas o meio pelo qual esse estudo se dá. Estes terão acesso desde o princípio ao projeto de pesquisa e assim poderão optar por aderir, ou não, à pesquisa.

O desenvolvimento da mesma envolve as três grandes áreas do conhecimento: Exatas, Humanas, Biomédicas, dentro destas escolhemos os Programas de Pós Graduação de Engenharia Civil, Odontologia e Educação da Universidade Federal de Uberlândia, uma vez que as duas primeiras possuem notas de destaque pela avaliação da CAPES (Coordenação de Aperfeiçoamento de Pessoal do Ensino Superior) e a última se refere ao programa que estamos diretamente ligadas.

A realização do diagnóstico a respeito do Estágio de Docência que aqui se relata envolve seis etapas diferentes, mas, ao mesmo tempo, complementares: $1^{\circ}$ etapa revisão bibliográfica; $2^{\circ}$ etapa- apresentação dos objetivos, fundamentos teóricos e metodológicos do estudo; $3^{\circ}$ etapa - elaboração e testes dos instrumentos de diagnóstico (questionários que serão aplicados) e análise dos documentos que explicitam a política de Estágio de Docência; $4^{\circ}$ etapa - aplicação de instrumentos. Serão envolvidos nesta parte da pesquisa os alunos de três programas de pós graduação da instituição que aceitaram o convite para participar e que estejam matriculados em Estágio de Docência. 
Eles responderão questões relacionadas à configuração dessa disciplina, objetivos, contribuições e obstáculos. Esses instrumentos pretendem apreender as expectativas dos discentes em relação à profissão e também, saber qual avaliação faz da formação inicial recebida e da sua provável contribuição no processo de profissionalização e desenvolvimento docente. As etapas seguintes envolvem: $5^{\circ}$ etapa - observação de aulas. Por intermédio de um instrumento de observação das atividades docentes, serão registrados aspectos observados dentro de dimensões distintas: a) formulação dos objetivos; b) seleção e tratamento dos conteúdos; c) integração dos conteúdos; d) métodos e procedimentos de trabalho; e) utilização dos meios de ensino; f) formas de organização da docência e; g) controle e avaliação da aprendizagem. A $6^{\circ}$ etapa - análise e discussão dos dados envolvem a análise e discussão dos dados os quais serão apresentadas na forma de relatório final.

\section{O ESTÁGIO DOCÊNCIA NA ÁREA DE EXATAS}

Dentre as três grandes áreas abordadas em nossa pesquisa, trazemos aqui as vivências de uma doutoranda (que terá seu nome preservado) na área de exatas. Os dados foram coletados por meio de entrevista semiestruturada, e refletem as impressões da bolsista acerca do que pôde experienciar durante a realização do estágio docência.

A bolsista diz ter sido comunicada da obrigatoriedade do estágio docência no momento da aprovação de sua bolsa, contudo não recebeu informações sobre a regulamentação do mesmo. Assim, de modo autônomo, buscou tais informações no site do Programa de Pós-Graduação ao qual estava vinculada.

O contato com a sala de aula propiciado pelo estágio permitiu a ela ter a primeira visão da docência como campo de atuação profissional, das dificuldades sobre o ser professor, dentre as quais destacou o interesse/envolvimento dos/as alunos/as. Ressaltando ainda que a posição ocupada pelo docente (a frente da sala de aula) possibilita ver o todo, as reações e ações dos demais sujeitos envolvidos no processo de ensino. Menciona também o fato de que a relação professor/aluno vivenciada cotidianamente pode ser fonte de frustação para o docente.

O planejamento das aulas ministradas foi realizado em parceira com o professor orientador, a bolsista fez uma seleção do conteúdo, atualização das normas vigentes e reestruturou a aula planejada pelo orientador. O recurso didático adotado foi data show, 
a exposição do conteúdo foi realizada de modo expositivo e a avaliação pensada por meio de exercícios de fixação. Cabe ressaltar, que durante a entrevista fica claro que a escolha por exercícios de fixação reflete a experiência positiva da bolsista como aluna, sendo esta uma forma pela qual ela diz "sempre aprender”. Para além das aulas ministradas, a bolsista assistiu às aulas ministradas por seu orientador e pode auxiliar os discentes na resolução de dúvidas.

O estágio docência também permitiu a ela perceber a necessidade de que o/a professor/a tenha amplo domínio sobre o conteúdo, que tenha clareza durante a exposição e a necessidade de ter “criatividade” tornando a aula mais dinâmica e menos pesarosa para os discentes. Estas são segundo a bolsista as principais contribuições do estágio docência para sua formação.

\section{CONCLUSÃO}

Os resultados neste trabalho revelam, até este momento, que há no cenário educacional a ausência de políticas públicas para a formação de professores para atuar no magistério superior. O texto da Lei 9.394/96 no Art. 52 apresenta a universidade como lócus da produção e da disseminação do conhecimento, e em seus incisos versa sobre a titulação necessária aos docentes que irão atuar nesse nível de ensino, e também sobre o regime de trabalho. É possível constatar que em embora a legislação exerça influência direta para o aumento na procura pelos cursos de pós-graduação, haja vista que estipula como índice mínimo a fração de um terço do corpo docente das universidades com formação no âmbito do stricto-sensu, ela se mostra frágil por não oferecer norteadores para a formação desses profissionais enquanto docentes. O que ocorre de forma distinta no que se refere à formação de professores em outros níveis de ensino. De certa forma, no caso da formação de professores para atuar na educação básica, há uma preocupação com o desenvolvimento de diferentes saberes e práticas pedagógicas, dentre elas as práticas de ensino, as metodologias e o estágio supervisionado, que englobam uma carga horária expressiva no novo desenho curricular para a formação de professores no Brasil. Em contrapartida, para o exercício da docência nos cursos técnicos e no ensino superior o foco é na competência científica, desprovida da dimensão didático-pedagógica. O que se constata no Art. 65 da mesma 
lei, pois este exclui a educação superior, da obrigatoriedade de cumprir a carga horária mínima estipulada para práticas de ensino.

Pode se perceber que há embutida nessa configuração a intenção de formar pesquisadores, tendo por base uma visão fragmentada do conhecimento, e implicitamente uma demarcação da divisão do trabalho. Acreditar que o bom pesquisador, é necessariamente um bom professor, é desconsiderar a importância de saberes específicos ao oficio da docência. O que nesse nível de ensino implica também em uma formação precária dos futuros profissionais que se destinaram a distintas áreas de saber e de atuação na sociedade. Logo a formação eficiente de professores para atuar no ensino superior implica em melhorias em todos os níveis de ensino.

Soares e Cunha (2010) chamam atenção para o fato de que a universidade é sobretudo uma instituição social, e que portanto visa atender a fins determinados. Ressaltam que aspectos inerentes à lógica do capital, como competitividade, eficiência e ampla produção, tem ditado a forma de organização dessa instituição. Situação que é referendada pela valorização de um "saber erudito", tendo como base uma noção positivista de ciência, onde a área de humanas não tem relevância. Asseveram ainda, que diante do acelerado desenvolvimento tecnológico, os discentes estão imersos em uma infinidade de informações, cabendo ao professor atuar como mediador e viabilizaruma formação crítica e reflexiva. Evidenciando que a contemporaneidade exige um professor diferente daquele chamado tradicional, pois o docente entendido como portador e transmissor do conhecimento, não mais atende aos anseios da sociedade.

Esses autores apontam vários aspectos que caracterizam a docência como um ofício complexo, dentre os quais se destacam a necessidade de articular saberes distintos, a interatividade entre professor e aluno, a singularidade do ensino voltado para adultos, e a relação em um espaço marcado pela multiplicidade de conhecimentos, valores e atitudes, e diferenças culturais.

Enfim, a docência do ensino superior é uma atividade complexa do ponto de vista político, social, intelectual, psicológico e pedagógico, cujos saberes e competências imprescindíveis ao seu exercício, [...] a configuram como campo específico de intervenção profissional. Dessa forma, como acontece com as demais profissões, não podem ser adquiridos por imitação, e, sim, mediante uma formação especifica e consistente. (SOARES e CUNHA, 2010, p.30) 
Diante da complexidade da docência, Soares e Cunha (2010) apontam como fator dificultador da construção de uma identidade docente, a precariedade da formaçãoinicial, embora esta não destitua o sujeito de saberes referentes à dimensão didático-pedagógica, contudo esse conhecimento esta pautado somente na leitura que o individuo faz dos seus antigos professores e de suas práticas. Em pesquisa empreendida por esses autores, foi possível constatar que os cursos de pós-graduação stricto senso tem como intenção primeira a formação de pesquisadores, embora a maior parte dos egressos desses cursos destine-se a atuação em sala de aula. Os sujeitos envolvidos na pesquisa afirmam que as principais contribuições do Programa de Pós Graduação para a sua formação, são a pesquisa, a publicação e o aprofundamento teórico delas decorrente, o que viria a implicar na melhoria das aulas ministradas. Contudo, explicitamente sobre a dimensão didático-pedagógica apresentaram apenas "formulações genéricas", e não houve formulações acerca da ética profissional. Evidenciando assim a ineficiência na formação desse profissional.

Neste momento da pesquisa, considera-se que o plano de trabalho permitirá aprofundar os estudos sobre a pedagogia universitária; compreender os fatores externos que impactam na formulação dos programas, tais como os aspectos sociais e os decorrentes das avaliações sistêmicas. Para, além disso, temos como pretensão contribuir com elementos teórico-metodológicos para a discussão sobre a relevância e especificidade da docência universitária e assim oferecer elementos para a construção de propostas que visem à melhoria na educação superior, tendo como premissa a formação docente em sua totalidade.

\section{REFERÊNCIAS}

SOARES, SR., and. CUNHA, MI. Formação do professor: a docência universitária em busca de legitimidade[online]. Salvador: EDUFBA, 2010. 134 p. ISBN 978-85-2320677-2.Available from SciELO Books <http://books.scielo.org>.

BRASIL. LDB: Lei de Diretrizes e Bases da Educação Nacional: Lei 9.394, de 20 de dezembro de 1996, que estabelece as diretrizes e bases da educação nacional [recurso eletrônico]. - 8. ed. - Brasília: Câmara dos Deputados, Edições Câmara, 2013. 45 p. (Série legislação; n. 102)

ALTET, Marie. As competências do professor profissional: entre conhecimentos, esquemas de ação e adaptação, saber analisar. In: PERRENOUD, $\mathrm{P}$ et al. Formando professores profissionais: quais estratégias? Quais competências? Porto Alegre: Artmed, 2001. 
BOGDAN, Roberto e BIKLEN, Sari K. Investigação Qualitativa em Educação. Trad. Maria João Alvarez, Sara B. Santos e Telmo Baptista. Porto: Editora Porto, 1994.

CHARLOT, Bernard. Formação de Professores: a pesquisa e a política educacional. In: PIMENTA, Selma G. e GHEDIN, Evandro (orgs.). Professor Reflexivo no Brasil. São Paulo: Cortez, 2002, pp. 81-88.

CUNHA, Maria Isabel da. O Bom Professor e a sua Prática. Campinas - SP, Papirus, 2001.

FREIRE, Paulo. Pedagogia da Autonomia: saberes necessários à prática educativa. 21 ed. São Paulo: Paz e Terra, 1996.

GARCÍA, C. M. Formação de professores. Para uma mudança educativa. Portugal: Porto Editora, 1995.

GIROUX, H. A. Os professores como intelectuais: rumo a uma pedagogia crítica da aprendizagem. Porto Alegre: Artmed, 1997.

IMBERNÓN, F. Formação docente e profissionalização. Formar-se para a mudança e a incerteza. $3^{\mathrm{a}}$. ed. São Paulo: Cortez Editora, 2002, 119p.

MELO, G. F. Tornar-se Professor: a formação desenvolvida nos cursos de Física, Matemática e Química da Universidade Federal de Uberlândia. Tese (Doutorado). Programa de Pós-graduação em Educação - Universidade Federal de Goiás Goiânia/GO, 2007. 232p.

MELO, G. F. et. all. A socialização profissional de professores e o desenvolvimento da identidade docente no Ensino Superior. Relatório de Pesquisa. CNPq. 2011.

NÓVOA, António (org.). Profissão professor. Porto: Porto Editora, 1995.

SACRISTÁN, J. Gimeno. Tendências Investigativas na Formação de Professores. In: PIMENTA, Selma G. e GHEDIN, Evandro (orgs.). Professor Reflexivo no Brasil. São Paulo: Cortez, 2002, pp. 81-88.

SHÖN, Donald. Formar professores como profissionais reflexivos. In: NÓVOA, A. (coord.) Os professores e sua formação. Lisboa: Dom Quixote, 1992.

ZEICHNER, Kenneth M. A formação reflexiva dos professores: idéias e práticas. Lisboa: Educa, 1993.

ZABALZA, M. L. O ensino universitário. Seu cenário e seus protagonistas. Porto Alegre: ArtMed, 2004. 